\title{
PLASMON-MEDIATED ELECTROCATALYTIC ACTIVITY OF TIB2 TOWARDS WATER SPLITTING
}

\author{
'Vladislav BURAVETS, ${ }^{1}$ Anna ZABELINA, ${ }^{1}$ Elena MILIUTINA, ${ }^{2}$ Daniela POPELKOVÁ, \\ ${ }^{3}$ Jiří HENYCH, ${ }^{2}$ Martin ŠŤASTNÝ, ${ }^{1}$ Vaclav ŠVORČíK, ${ }^{1}$ Oleksiy LYUTAKOV \\ 1University of Chemistry and Technology, Prague, Czech Republic, EU, info@vscht.cz \\ 2Institute of Inorganic Chemistry of the Czech Academy of Sciences, Husinec-Řež, Czech Republic, EU, \\ sekretar@iic.cas.cz \\ 3Jan Evangelista Purkyně University, Ústí nad Labem, Czech Republic, EU, incoming@ujep.cz
}

https://doi.org/10.37904/nanocon.2021.4341

\begin{abstract}
Environmental problems related to the economy based on fossil fuels are of paramount importance. However, transition to renewable energy sources is restrained by the availability of storage technologies. Electrochemistry is a widely recognized prominent tool to achieve this goal by converting renewable energy into the form of chemical bonds accessible further as fuels, such as hydrogen produced by water splitting. Crucial losses in such process are caused by the high overpotentials, required for water splitting as a hydrogen source. To achieve required efficiency of water splitting appropriate catalysts have to be found with the suitable combination of activity, stability and cost. Nano-structured, two-dimensional materials (2D) are attractive candidates due possessing many of the desired properties and highly tunable characteristics. Employing light allows additional degree of freedom to boost conventional photo-electrocatalysis, in particular plasmonmediated electrocatalysis. Enhancement of the catalytic activity can be increased even further if the catalytic system absorbs wide range of light spectrum. In this study, we combine plasmon-active Au grating with 2D flakes of $\mathrm{TiB}_{2}$, to perform plasmon-mediated water splitting half-reaction - hydrogen evolution.
\end{abstract}

Keywords: Hydrogen evolution, photo-electrocatalysis, plasmonics, 2D materials

\section{INTRODUCTION}

Nowadays society consumes on the range of $16 \mathrm{TW}^{*}$ hours of primary energy per year, with $84.3 \%$ of it coming from fossil fuels [1]. This causes a significant impact on the environment being one of the major causes of climate crisis. In order to switch for renewable energy sources to mitigate impact on the environment, a method for efficient storage and use on demand of this energy has to be found. Hydrogen is a prominent candidate for such a purpose due to high energy density and water as the only by-product during combustion [2]. Efficient water electrolysis is an important technology for energy conversion into $\mathrm{H}_{2}$ for the sustainable society [3,4]. A targeted catalytic activity is proposed to require overpotential lower than $0.45 \mathrm{~V}$ combined for both halfreactions - oxygen evolution reaction (OER) and hydrogen evolution reaction (HER) [5]. Thus, different opportunities to enhance both half-reactions are required. A promising approach to enhance catalytic activity is to employ light and plasmonic materials to enhance the light absorption and widen range of useful light spectrum [6]. The plasmonic resonant wavelength depends on the material, size and shape of the catalyst and can be fine-tuned by manipulating this variables [7].

In this work, we propose a model to enhance catalytic activity towards HER by combining plasmon-active materials and 2D flakes ( $\left.\mathrm{TiB}_{2}\right)$. Proposed approach allows us to significantly increase the HER efficiency, under the plasmon assistance in photo-electrochemical process. 


\section{EXPERIMENTAL PART}

\subsection{Materials}

Au target for metal deposition (4N purity) was purchased from Safina (Czech Republic). Sulfuric acid, titanium boride $\left(\mathrm{TiB}_{2}\right)$, chloroauric acid $\left(\mathrm{HAuCl}_{4}\right)$, trisodium citrate $\left(\mathrm{Na}_{3} \mathrm{C}_{6} \mathrm{H}_{5} \mathrm{O}_{7}\right)$ were purchased from Sigma-Aldrich.

\subsection{Sample preparation}

For AuNPs synthesis Turkevich method was used [8]. AuNPs were synthesized by reduction of gold from the $\mathrm{HAuCl}_{4}$ solution initialized by sodium tris-citrate. For preparation of Au-grating a commercially available polymer grating were used as template and covered by thin gold layer. $\mathrm{TiB}_{2} 2 \mathrm{D}$ flakes were obtained by exfoliation in water/alcohol mixture under the high-power ultrasound treatment.

\subsection{Characterization methods}

Ultraviolet-visible spectra were measured using Spectrometer Lambda 25 (Perkin-Elmer). Crystal structure of the $\mathrm{TiB}_{2}$ was investigated by XRD technique (PANalytical X'Pert PRO). The micro-morphology and elemental analysis of the samples were performed by high-resolution transmission electron microscopy EFTEM Jeol 2200 FS microscope (Jeol, Japan). Linear sweep voltammetry measurements were carried out with PalmSense4 potentiostat, controlled by PSTrace5 software. Experiments were performed in a $15 \mathrm{ml}$ quartz cuvette, using a three-electrode configuration at room temperature, with platinum and $\mathrm{Ag} / \mathrm{AgCl}$ electrodes as counter and reference, respectively. The LEDs light sources (Thorlabs) with different wavelengths were placed at a distance of $\sim 1 \mathrm{~cm}$ from sample surface and the power on sample surface was adjusted to $0.4 \mathrm{~W} / \mathrm{cm}^{2}$.

\section{RESULTS AND DISCUSSION}

First, delaminated $\mathrm{TiB}_{2}$ flakes were subjected to XRD measurements. Results are presented in Figure 1 and indicate that obtained XRD pattern correspond well with previously published (reference number 03-0651073).

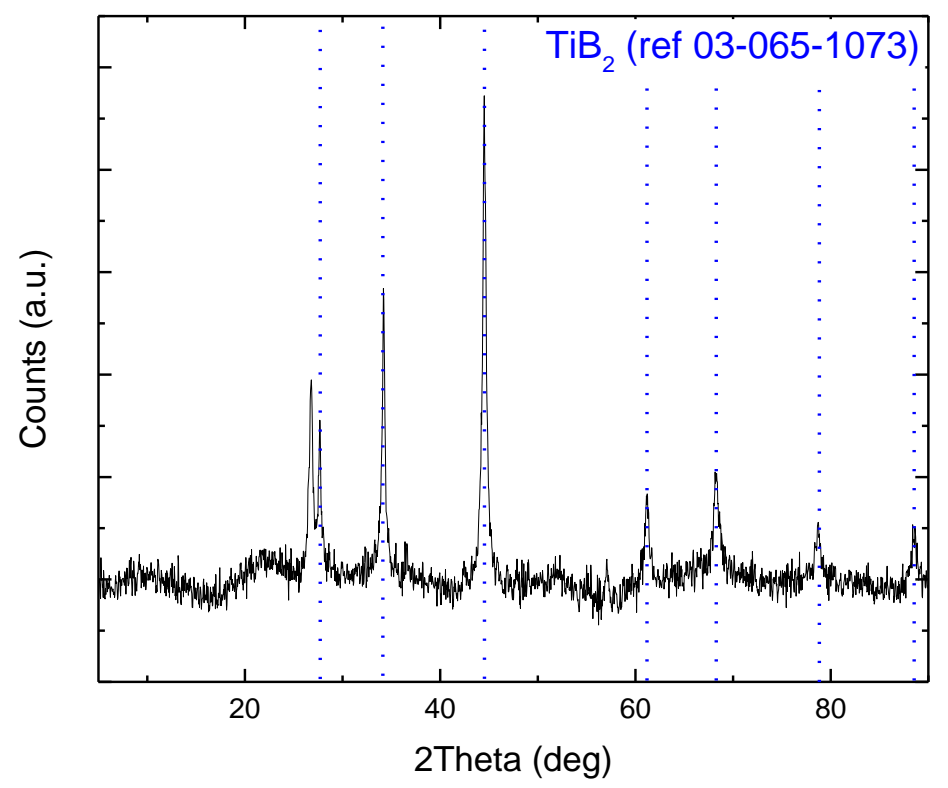

Figure $1 \mathrm{XRD}$ diffraction pattern of ultrasonicated $\mathrm{TiB}_{2}$

The absorption of all used materials (i.e. 2D flakes, gold nanoparticles and gold grating) are presented in Figure 2. It can be seen, that main absorption peaks are spectrally separated, which should ensure the 
excellent overlapping with sunlight spectrum and allow to utilize sunlight spectrum in plasmon*-assisted photoelectrochemical water splitting.

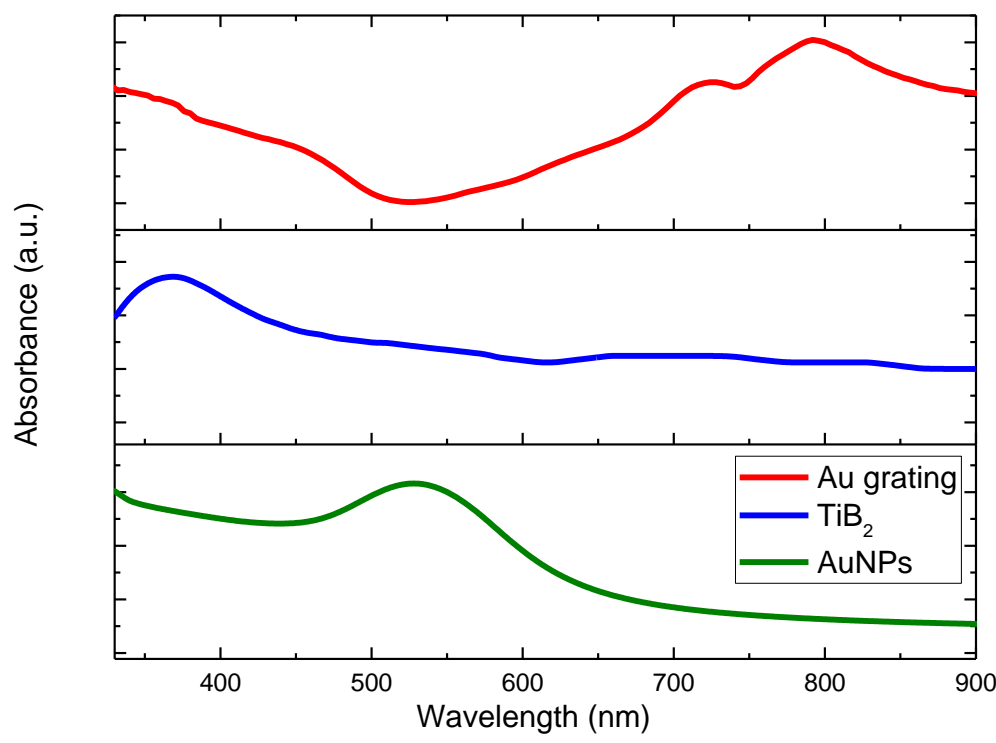

Figure 2 UV-Vis spectra of the Au grating (red), ultrasonicated TiB2 (blue) and Au nanoparticles (green)

\section{$\mathrm{TiB}_{2}$}
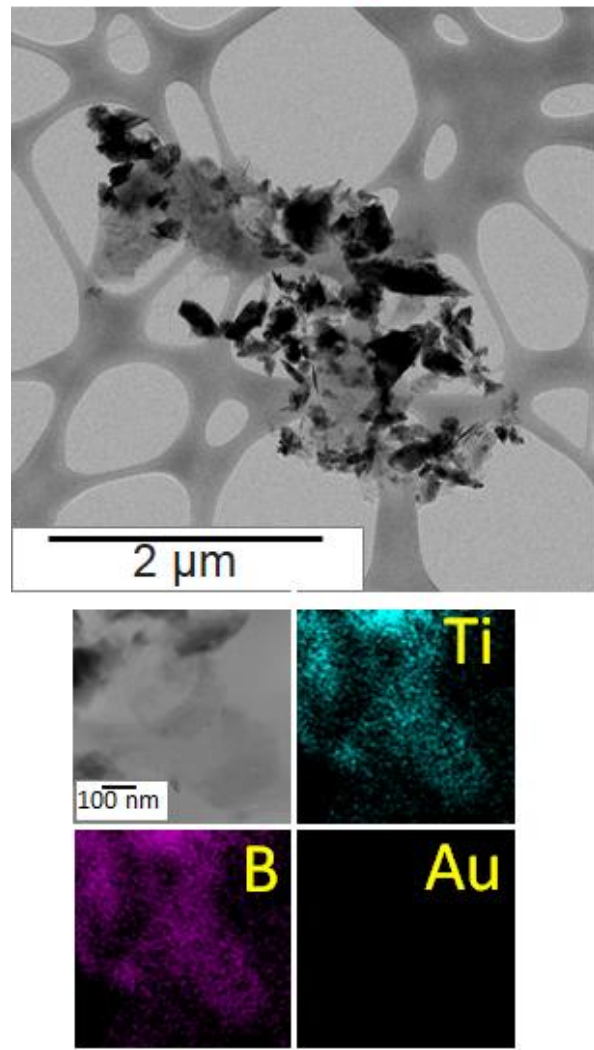

\section{$\mathrm{TiB}_{2} @$ AuNPs}
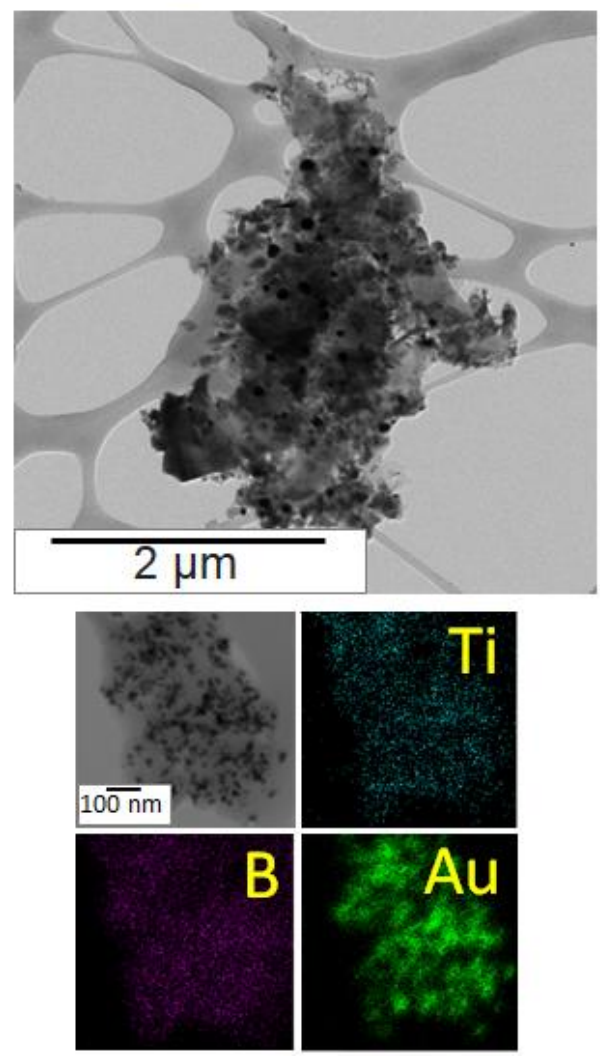

Figure 3 TEM images (top) and TEM/elemental mapping merged images (bottom) of TiB2 paticle (left) and TiB2 particle populated with AuNPs (right) 
In Figure 3 TEM images and TEM-EDX elemental mapping are presented. It can be seen that $\mathrm{TiB}_{2}$ particles are of the similar size after modification with AuNPs. In turn, TEM-EDX mapping indicates that after surfaceassisted grafting of nanoparticles, the $\mathrm{TiB}_{2}$ flakes surface are uniformly covered by AuNPs.

Linear sweep voltammetry (LSV) experiments, performed in dark or under illumination are shown in Figure 1. It is evident that Illumination of Au grating with red light (Figure 4A) resulted in the increase of current, hence, rate of the hydrogen evolution reaction. However, illuminating by the blue or green light did not result in the further enhancement of the catalytic activity. When $\mathrm{TiB}_{2}$ was deposited on the Au grating (Figure 4B) it was possible to harvest light of wider spectral range which also caused increase of the HER rate. Illuminating such system as $\mathrm{TiB}_{2} / \mathrm{Au}$ grating with red light resulted in similar current as obtained for the solely Au grating, while blue and green lights caused further increase in the current. Recorded currents under the green and blue lights were very similar on the $\mathrm{TiB}_{2} / \mathrm{Au}$ grating. Finally, to harvest the light of green spectrum, AuNPs were seeded on $\mathrm{TiB}_{2}$. Current response of such system is shown in (Figure $\mathbf{4 C}$ ). It can be seen, that a further increase of materials HER catalytic activity under illumination by green light was achieved. So, we are showing, that different combination of plasmon active and catalytic-active 2D materials with different absorption wavelengths allows to increase the light harvesting with corresponded enhancement of photo-electrochemical catalytic activity towards hydrogen evolution reaction.
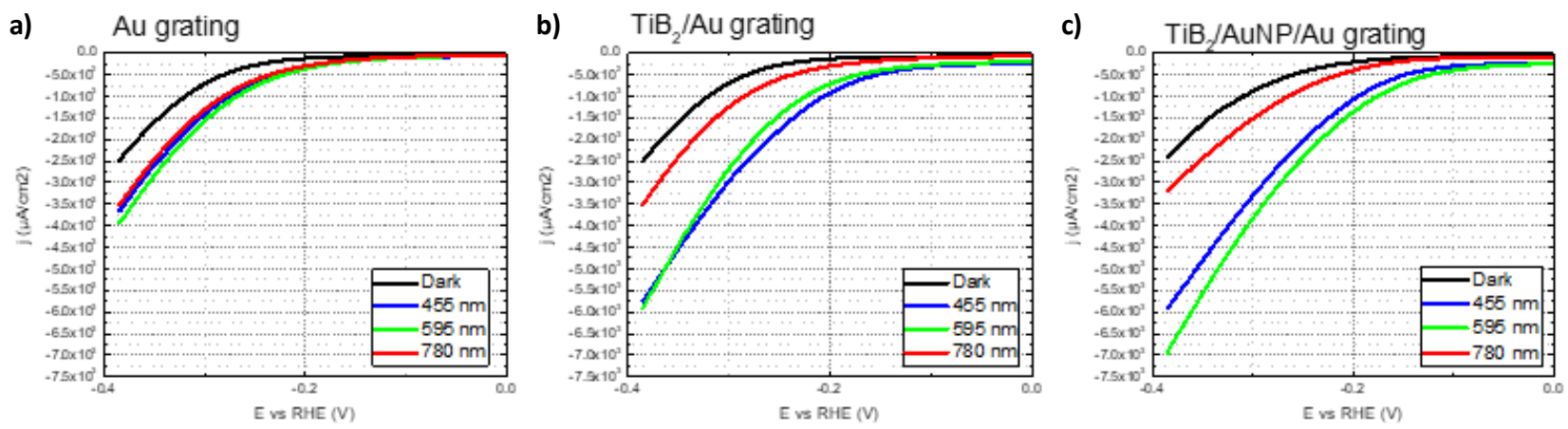

Figure 4 Linear sweep voltammetry (LSV) of Au grating (a), TiB2/Au grating (b) and TiB2/AuNPs/Au grating (c) in dark and under LED illumination with wavelengths $455 \mathrm{~nm}$ (blue), $595 \mathrm{~nm}$ (green) and $780 \mathrm{~nm}$ (red)

\section{CONCLUSION}

A system to harvest different range of (sun)light spectrum was proposed based on the different combination of plasmon active materials (Au grating and AuNPs) and catalytically-active $2 \mathrm{D}$ flakes $\left(\mathrm{TiB}_{2}\right)$. Each of three components has shown its own peak of absorbance in the visible and near UV ( $365 \mathrm{~nm}$ ) wavelength range. Created hybrid systems were tested for its photo-electrocatalytic activity towards HER. The samples structure and materials coupling was characterized/confirmed using XRD, UV-Vis, and TEM-EDX techniques. The functionality of created materials was checked in water splitting half-reaction - hydrogen evolution using the photo-electrochemical measurements in LSV mode (performed in dark or under illumination). A significant increase in current was achieved under illumination by light with different wavelengths allowing potential enhancing HER rate by wide range of light spectrum. In particular it was shown, that plasmon triggering and corresponded increase in catalytic activity $\mathrm{TiB}_{2}$ can be significantly reached under the application of wavelengths, corresponded to plasmon absorption band.

\section{ACKNOWLEDGEMENTS}

This work was supported by the MV, VS IMPAKT 1, grant number VJ01010065. 


\section{REFERENCES}

[1] bp global. Statistical Review of World Energy. [online]. 2021. [viewed 2021-11-07] Available from: https://www.bp.com/en/global/corporate/energy-economics/statistical-review-of-world-energy.html.

[2] TURNER JA. Sustainable Hydrogen Production. Science. [online]. 2004, no. 305, pp. 972-974. Available from: https://doi.org/10.1126/science.1103197.

[3] GUSELNIKOVA, O., TRELIN, A., MILIUTINA, E., ELASHNIKOV, R., SAJDL, P., POSTNIKOV, P., KOLSKA, Z., SVORCIK, V., LYUTAKOV, O. Plasmon-induced water splitting-through flexible hybrid 2D architecture up to hydrogen from seawater under NIR Light. ACS Appl Mater Interfac. [online]. 2020, no.12, pp. 28110-28119. Available from: https://doi.org/10.1021/acsami.0c04029.

[4] ZABELINA, A., ZABELINA, D., MILIUTINA, E., LANCOK, J., SVORCIK, V., CHERTOPALOV S., \& LYUTAKOV, $\mathrm{O}$. Surface plasmon-polariton triggering of Ti $3 \mathrm{C} 2 \mathrm{~T} \times \mathrm{MXene}$ catalytic activity for hydrogen evolution reaction enhancement. J Mater Chem A. [online]. 2021, no. 9, pp.17770-17779. Available from: https://doi.org/10.1039/D1TA04505A.

[5] MCRORY CCL, JUNG S, FERRER IM, CHATMAN SM, PETERS JC, JARAMILLO TF. Benchmarking Hydrogen Evolving Reaction and Oxygen Evolving Reaction Electrocatalysts for Solar Water Splitting Devices. J Am Chem Soc. [online]. 2015, no. 137, pp.4347-4357. Available from: https://doi.org/10.1021/ja510442p.

[6] $\mathrm{CHOI} \mathrm{CH,} \mathrm{CHUNG} \mathrm{K,} \mathrm{NGUYEN} \mathrm{T-TH,} \mathrm{KIM} \mathrm{DH.} \mathrm{Plasmon-Mediated} \mathrm{Electrocatalysis} \mathrm{for} \mathrm{Sustainable} \mathrm{Energy:} \mathrm{From}$ Electrochemical Conversion of Different Feedstocks to Fuel Cell Reactions. ACS Energy Lett. [online]. 2018, no. 3, pp. 1415-1433. Available from: https://doi.org/10.1021/acsenergylett.8b00461.

[7] LINIC S, CHRISTOPHER P, INGRAM DB. Plasmonic-metal nanostructures for efficient conversion of solar to chemical energy. Nature Mater. [online]. 2011, no. 10, pp. 911-921. Available from: https://doi.org/10.1038/nmat3151.

[8] KIMLING J, MAIER M, OKENVE B, KOTAIDIS V, BALLOT H, PLECH A. Turkevich Method for Gold Nanoparticle Synthesis Revisited. J Phys Chem. [online]. 2006, no. 110, pp. 15700-15707. Available from: https://doi.org/10.1021/jp061667w. 